\title{
O DESENVOLVIMENTO LOCAL POR MEIO DAS FINANÇAS SOLIDÁRIAS: A MOEDA SOCIAL COMO INSTRUMENTO DE FORTALECIMENTO DA ECONOMIA POPULAR SOLIDÁRIA.
}

\author{
SILVA, Sara de Souza1; LIMA, José Raimundo Oliveira² \\ ${ }^{1}$ Bolsista de Iniciação Científica PIBIC/ CNPq, Graduanda em Ciências Econômicas pela Universidade Estadual de Feira de \\ Santana: $\underline{\text { sarah.silva58@ hotmail.com. }}$ \\ 2 Orientador, Departamento de Ciências Sociais Aplicadas, Coordenador do Programa de Extensão e Pesquisa \\ Incubadora de Iniciativas da Economia Popular e Solidária da Universidade Estadual de Feira de Santana: \\ zeraimundo@uefs.br.
}

PALAVRAS-CHAVE: Finanças solidárias; Economia popular e solidária; Desenvolvimento local; Moeda social.

\section{INTRODUÇÃO}

A Incubadora de Iniciativas da Economia Popular e Solidária da UEFS (IEPS-UEFS) se afirma como uma ação na luta pelo fortalecimento da cidadania e do desenvolvimento local, com o objetivo de articular a educação acadêmica com a cultura e a educação popular, através da prática de incubação de grupos que se organizam nos princípios da economia popular e solidária, são algumas tipologias organizativas as cooperativas, associações, clubes de troca, entre outros, cujo grupos realizam atividades de produção de bens, prestação de serviços e comercio justo. A IEPS articula a integração do Ensino, Pesquisa e Extensão e a atuação de pesquisadores e formadores no quadro de uma ação formativa que compõe a proposta pedagógica da Incubadora conforme discute Lima (2011).

O desenvolvimento local é uma forma de democratização, não apenas de acesso ao crédito, mas também de participação no processo econômico, promoção e inclusão financeira no desenvolvimento das comunidades locais por meio de instrumentos que fomentam as finanças solidárias como, por exemplo, a moeda social., entretanto, não se pode pensar em desenvolvimento sem inclusão financeira. As Finanças Solidárias possibilitam essa democratização de acesso ao credito.

Diante do exposto o objetivo desse trabalho é refletir sobre os instrumentos financeiros e como as iniciativas fazem para ter acesso a financiamentos e como a moeda social enquanto instrumento das finanças solidárias poderá articular o acesso ao credito que possibilita $\mathrm{o}$ desenvolvimento local.

\section{DESCRIÇÃO DOS MATERIAIS E MÉTODOS UTILIZADOS}

O trabalho parte da perspectiva de pesquisa participante e pesquisa ação que será visita de campo às iniciativas, como o grupo em questão é o Sabores do Quilombo que está atualmente instalado na cantina do Módulo I do campus dessa universidade ao qual está vinculado ao Projeto Cantina Solidária III, orientado pela IEPS.

Serão também realizadas visita a cooperativas de crédito para entender como funciona a liberação de credito às iniciativas.

Outro instrumento utilizado será a possibilidade de utilização da moeda social O SERTANEJO, uma vez que a mesma já foi utilizada em um evento nesta universidade, uma vez que esta possibilita o entendimento de como funciona a dinâmica da economia popular e solidária para 
o desenvolvimento local, pois mostra de maneira simples a relação do sujeito com a moeda, haja vista que a mesma tem um papel diferente no modelo tradicional, sendo que a moeda transformou-se em uma mercadoria; já para o desenvolvimento local a moeda social retoma a sua forma original que é a função de troca.

\section{RESULTADOS E/OU DISCUSSÃO}

A compreensão efetivamente da relevância de proposições que visam o fortalecimento do desenvolvimento local por meio das finanças solidárias conforme Singer (2009), articuladas entre as iniciativas de economia popular e solidária orientadas pelo Programa da Incubadora de Iniciativas de Economia Popular e Solidária da UEFS, foi por meio de estudo e conhecimento sobre a função dos Bancos Comunitários das Moedas Sociais.

O Sertanejo foi testado no I Congresso Internacional de Economia Popular e Solidaria Desenvolvimento Local: diálogo Brasil-Cuba, e teve grande aceitação entre os participantes e expositores.

O comentário mais frequente entre os expositores foi de que o sertanejo facilitou o troco, uma vez que os participantes faziam a conversão da moeda no Banco Comunitário e já levavam o dinheiro trocado para realizar a compra ou acontecia de muitos participantes trocaram a moeda real pelo sertanejo para levarem as suas comunidades, essa atitude e mostrar que a moeda social cumpriu a sua função pedagógica e acadêmica(pelos estudos realizado para testes comparativos com a moeda convencional), pois todos que participaram da feira puderam entender $o$ funcionamento da moeda social e a importância dela no desenvolvimento local, conforme discute Lima (2014).

Abaixo estão as moedas e seus respectivos significados e representação social.

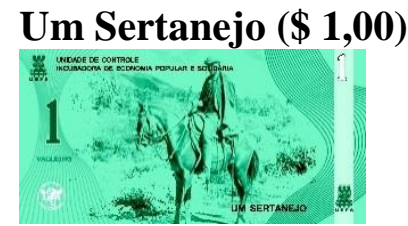

\section{Vaqueiro}

$\mathrm{O}$ vaqueiro é a figura central de uma fazenda e também seu operador, pois o patrão geralmente é ou foi um vaqueiro. Seu trabalho é árduo e contínuo, mas, bem representativo no sertão nordestino.

\section{Dois Sertanejos $(\mathbf{2 , 0 0})$}

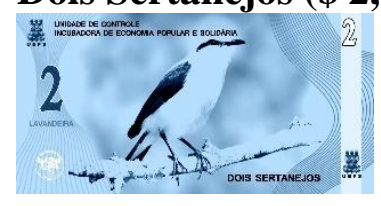

\section{Lavandeira}

Por conta do nome ligado a religiosidade, os caçadores nordestinos não a matam nem a comem, por isso, ao contrário da extinção, como é o caso da maioria das aves da região, ela se encontra em expansão.

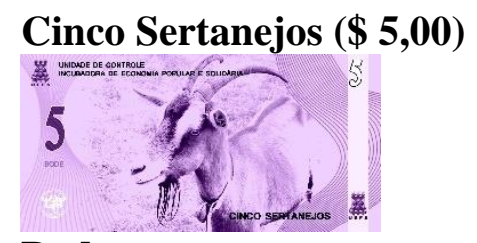

\section{Bode}

É um animal robusto que pode viver em grama áspera e escassa e ser criado em terrenos que não tenham plantas suficientes para vacas, grandes animais ou carneiros, como é o caso do sertão nordestino.

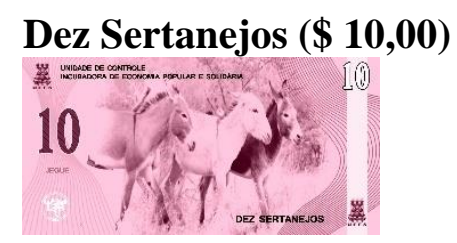

\section{Jegue}

Este animal integrou-se com facilidade às necessidades de transporte do sertão, pela sua rusticidade, força, longo tempo sem necessidade de comer nem beber água. 
Essa ilustração trata-se da moeda social O Sertanejo que circulou no I congresso de Economia Popular e Solidária da UEFS é uma demonstração parcial de execução do plano de trabalho haja vista que houve a necessidade de demostrar as moedas pois trata-se de um instrumento de finanças solidária, que durante o seu uso na I Feira de Economia Popular e Solidária da UEFS houve facilidade e aceitação do público quanto ao seu uso.

\section{CONSIDERAÇÕES FINAIS}

É possível observar nas finanças solidárias uma estratégia com o objetivo social de inclusão financeira, pois como se sabe os bancos capitalistas ou bancos públicos não dão a devida oportunidade para pessoas pobres ou que se encontram à margem da extrema pobreza. Com isso, vislumbra-se a necessidade finanças solidárias articuladas a microcrédito ou credito orientado para a iniciação e atuação do micro organização popular.

Esse projeto de pesquisa/extensão visa contribuir para o melhor entendimento do que seja as finanças solidarias e proporcionar o fortalecimento do desenvolvimento local por meio das finanças solidárias, articuladas entre as iniciativas de economia popular e solidária orientadas pelo programa incubadora de iniciativas de economia popular e solidária da UEFS.

A moeda será numerada em série, o que servirá como controle da sua circulação evitando falsificação, entre outros problemas como por exemplo 0,50 - 1000 cédulas de numeração de série 0001 A 1000.

O Banco Comunitário Sertanejo funcionará também como uma "Casa de Câmbio" para as trocas do real pelo sertanejo e vice-versa a "Casa de Câmbio" será, a princípio, também Projeto de Extensão da IEPS/UEFS que será responsável pela emissão, controle, distribuição e retirada do sertanejo de circulação. Os produtos comprados no sistema com a moeda social, quando for o caso terá desconto ou preço justo por integrar ao sistema de economia popular e solidária com circulante local.

Portanto, as reflexões ao longo dos nossos estudos dão conta de que a moeda social se constitui em relevante instrumento das finanças solidárias que articulado pela economia popular e solidária possibilita o desenvolvimento local.

\section{REFERÊNCIAS}

Projeto Incubadora de Iniciativas da Economia Popular e Solidária da Universidade Estadual de Feira de Santana. Feira de Santana, Bahia, 2008.

\section{LIMA, J. R. O. A Economia Popular e Solidária como possibilidade para o} Desenvolvimento Local Solidário. Conferência realizada na Casa do Trabalhador em 2011. Feira de Santana. Semana do Trabalhador Organizada pela Secretaria de Desenvolvimento Econômico de Feira de Santana-BA.

LIMA, J. 2014. A Economia Popular e Solidária como estratégia para o desenvolvimento local solidário no município de Feira de Santana - Bahia. Salvador, BA. Tese de Doutoramento. Universidade Estadual da Bahia, 335 p. 
SINGER, P. Finanças Solidárias e Moeda Social. In: FELTRIM, L. E.; VENTURA, E. C. F.; DODL, A. V. B. (Coord.). Perspectivas e desafios para a inclusão financeira no Brasil. Brasília: Banco Central do Brasil, 2009. 